\title{
Recording of patient weight in the intensive care unit: a survey of current practice
}

\author{
S Birkholzer ${ }^{1 *}$, N Richardson² ${ }^{2}$ E Fitzgerald ${ }^{1}$, B Harris ${ }^{1}$, J Knighton ${ }^{1}$ \\ From ESICM LIVES 2015 \\ Berlin, Germany. 3-7 October 2015
}

\begin{abstract}
Introduction
A recent single-centre audit uncovered inadequacies in the practice of measuring and recording of patient body weight (BW), and knowledge of weight based clinical calculations in ICU. To further investigate this, we distributed and promoted a multi-disciplinary survey to assess current practice and knowledge in all ICU's in the Wessex region, UK.
\end{abstract}

\section{Objectives}

The aim was to identify areas of good practice and implement this practice in all ICUs in the Wessex region.

\section{Methods}

A survey was distributed to the multidisciplinary team in 12 ICUs. The following were included: responder job position, practice for weight and height recording in their ICU, and knowledge of what type of BW measurement should be used for a variety of drug dosing and lung protective ventilation (LPV) calculations.

\section{Results}

451 responses were received. Nurses 60\% ( $\mathrm{n}=270)$, Doctors in training 22\% ( $\mathrm{n}=98)$, Consultants $13 \%(\mathrm{n}=$ 57) and other healthcare professionals $3.5 \%(\mathrm{n}=16)$, 10 did not state their occupation. $48 \%$ of respondents replied that BW documented on admission was estimated. When BW was actually measured or calculated, $69 \%$ used actual BW (ABW) and 28\% ideal BW (IBW), some both. The recorded height was measured by $52 \%$ of responders, estimated by $31 \%$ and derived from forearm or tibia length by $20 \%$.

'Portsmouth Hospital NHS Trust, Department of Critical Care, Portsmouth,

United Kingdom

Full list of author information is available at the end of the article
$57 \%$ of responders correctly identified that IBW or predicted BW should be used for LPV. $21 \%$ of consultants answered incorrectly, 18\% did not answer.

Exceptional good practice was demonstrated in one institution where BW was measured or calculated by $100 \%$ of 40 responders. In this ICU $100 \%$ of respondents knew that either ideal or predicted BW in used to calculate desired tidal volume as part of LPV.

When analysing answers to the drug dosing questions, only doctors and pharmacists were included $(\mathrm{n}=161)$. $35 \%(\mathrm{n}=56)$ correctly indicated that ABW should be used to calculate Suxamethonium dosage in obese patients.53\% ( $\mathrm{n}=86), 37 \%$ and $36 \%$ knew that dosing of unfractionated heparin, Gentamycin and Vancomycin respectively in non-obese patient is based on the ABW.

\section{Conclusions}

Measurement and recording of accurate BW and height is inconsistent and poor in most of the ICUs surveyed. There are significant knowledge gaps in identifying what BW should be used for a variety of clinical and pharmacological drug calculations. Errors and lack of knowledge may result in ineffective treatment and unsafe quantities of therapeutic interventions like LPV.

Following this survey, compliance with LVP was audited in these ICUs. It demonstrated that in the institution where accurate documentation of $\mathrm{BW}$ and height is mandatory on admission, the compliance with LVP at $8 \mathrm{ml} / \mathrm{kg}$ was significantly better than any ICU in Wessex (100\% compliance).

Local leads have presented the results of the survey and promoted documentation of ABW and height as a mandatory part of ICU admission. Following the education process, compliance with documentation of measured BW and height will be audited. 


\section{Authors' details}

'Portsmouth Hospital NHS Trust, Department of Critical Care, Portsmouth,

United Kingdom. ${ }^{2}$ University of Southampton NHS Foundation Trust,

Department of Critical Care, Southampton, United Kingdom.

Published: 1 October 2015

doi:10.1186/2197-425X-3-S1-A918

Cite this article as: Birkholzer et al: Recording of patient weight in the intensive care unit: a survey of current practice. Intensive Care Medicine Experimental 2015 3(Suppl 1):A918.

\section{Submit your manuscript to a SpringerOpen ${ }^{\mathcal{O}}$ journal and benefit from:}

- Convenient online submission

- Rigorous peer review

- Immediate publication on acceptance

- Open access: articles freely available online

- High visibility within the field

- Retaining the copyright to your article

Submit your next manuscript at $\gg$ springeropen.com 